\title{
Sentinel node mapping during laparoscopic distal gastrectomy for gastric cancer
}

\author{
Elena Orsenigo $\cdot$ Carlo Staudacher
}

Published online: 30 January 2009

(C) Springer Science+Business Media, LLC 2009

We appreciate the opportunity to answer to the comments of Drs. Sporn, Miedema, Thaler, and Davis on our article entitled "Sentinel node mapping during laparoscopic distal gastrectomy for cancer," which appeared in the January 2008 issue of Surgical Endoscopy [1].

In this study we addressed the feasibility of using the sentinel node technique in treating gastric cancer to explore its usefulness during minimal invasive surgery. We want to thank the reviewers for the thoughtfulness of their comments. We agree with them that it is important to assess the quality of the statistical analysis. We therefore agree with them on the narrowness of our casuistry. This should result in a more tempered enthusiasm. Nevertheless, we maintain that the goal of our paper was to demonstrate that laparoscopic sentinel node mapping in gastric cancer is feasible also by using minimally invasive approach. Our main message is not to suggest the replacement of standard D2 lymphadenectomy, but only to evaluate the feasibility of sentinel node mapping with endoscopic submucosal blue dye injection during laparoscopic distal gastrectomy for gastric cancer.

So far, sentinel node mapping in gastric cancer has been used to study the lymphatic basin of the stomach. This technique is particularly helpful when the lymphatic drainage could be changed by the tumor invasion. As lymph node metastasis is one of the most prognostic factors in patient with gastric cancer, the identification of a conservative diagnostic approach will be a new diagnostic tool. Therefore, we aimed to explore and identify ways to further optimize the diagnosis of node metastasis in gastric cancer. We do believe it is our duty to report that this technique is feasible due to its potential clinical relevance.

To strengthen our report, more cases will be needed (and are on their way) before an optimal strategy in laparoscopic gastric resection with sentinel node biopsy for gastric cancer can be established. Further studies on technical issues, including indications, tracers, methods of lymph node retrieval, and diagnostic modalities of metastasis will validate this technique.

\section{Reference}

1. Orsenigo E, Tomajer V, Di Palo S, Albarello L, Doglioni C, Masci E, Viale E, Staudacher C (2008) Sentinel node mapping during laparoscopic distal gastrectomy for gastric cancer. Surg Endosc 22:118-121
E. Orsenigo $(\bowtie) \cdot$ C. Staudacher

Department of Surgery, University Vita-Salute San Raffaele,

Milan, Italy

e-mail: orsenigo.elena@hsr.it 